\title{
USING AN ALTERNATIVE LIGHT SOURCE IN CURING POLYESTER P40
}

\author{
D. Sivrev, N. Dimitrov
}

\author{
Department of Anatomy, Faculty of Medicine, Trakia University, Stara Zagora, Bulgaria
}

\begin{abstract}
Impregnation of brain sections with polyester P40 is a modern method for making brain plates. Use a special glass chamber for imparting a form of preparations. Artificial UV radiation is used for cerebral plates production. There have been successful attempts to use a mercury lamp as a catalyst for the polymerization of polyester. As ultraviolet sources and mercury lamps are expensive source of UV radiation, which increases the value of the resulting anatomical preparations. We use the sun's rays in the early and late in the day for hardening Biodur P40 in the development of brain plates. The basic requirement is the intensity of solar radiation to be not high, as rapid polymerization causes shrinkage and cracking of the protective polyester film. Thus curing brain plates is slower than classic curing, but allows continuous control of the curing process of brain slices. The resulting anatomical preparations are of high quality and can be successfully used for training of medical and veterinary students.
\end{abstract}

Key words: plastination, Biodur, P40, safety anatomical preparations, UV, mercury lamp

\section{INTRODUCTION}

Impregnation of brain sections with polyester P40 is a modern method for making brain plates. This impregnation method is a successor of P35 classic method for brain slices making. According $\ddot{U} z e l$ P35 is used to obtain semitransparent brain slices with excellent gray-white matter distinction (1). There are four steps in P35 plastination procedure: fixation, dehydration, impregnation and light curing stage (2). Water formaldehyde solution $8-10 \%$ is usually used for fixation of the brain. Weiglein slices the brain on stainless steel saw and put it in $+5^{\circ} \mathrm{C}$ dehydrator (2). Von Hagens, Weiglein and Weber (2007) use a special double glass chamber for imparting a form of preparations $(2,3.4)$.

The hardeners for Biodur P35 and P40 are UV rays. Curing was started using UVA-light on both sides of the specimen for 3 hours (2). The same author indicates that ventilation is very important during light curing. The ventilation support temperature bellow $35^{\circ} \mathrm{C}$ in the embedding chamber. Suriyaprapadilok and Withyachumnarnkul use color injections for achievement of stained sections of the human brain (5).

The history of all plastination methods is described by Pashaei (6) in a brief review on the history, methods and applications of plastination. Plastination is an expensive method in anatomy conservation. Using of electrical UV sources additional raise the cost of final preparations.

\section{AIM AND PURPOSES}

The aim of this investigation is to compare the quality and price of the $\mathrm{P} 40$ brain slices hardened by UV-light lamp and by sunny light.

For achievement of this aim we plan the next purposes:

1. Making brain slices using UV-light lamp in curing stage.

2. Making brain slices using sunny light in curing stage.

3. Make comparison between these two curing techniques.

\section{MATERIAL AND METHODS}

We used fixated brains got at the time of educational dissections with second medical course. The brain is cut preliminary to slices 4 $\mathrm{mm}$ thick. Brain plates was plunged for dehydration in cool $\left(+5^{\circ} \mathrm{C}\right)$ aceton. The dehydration time was 3 days since the thickness of brain slices was $4 \mathrm{~mm}$ only. We used one dehydration bath and one immersion bath with Biodur P40 mixture for 24 hours. The next step was brain impregnation in double glass chamber that was filled with 
Biodur P40 and the brain slice was positioned in the resin mixture.

There have been successful attempts to use a mercury lamp as a catalyst for the polymerization of polyester. As ultraviolet sources and mercury lamps are expensive source of UV radiation, which increases the value of the resulting anatomical preparations (Figure 1).

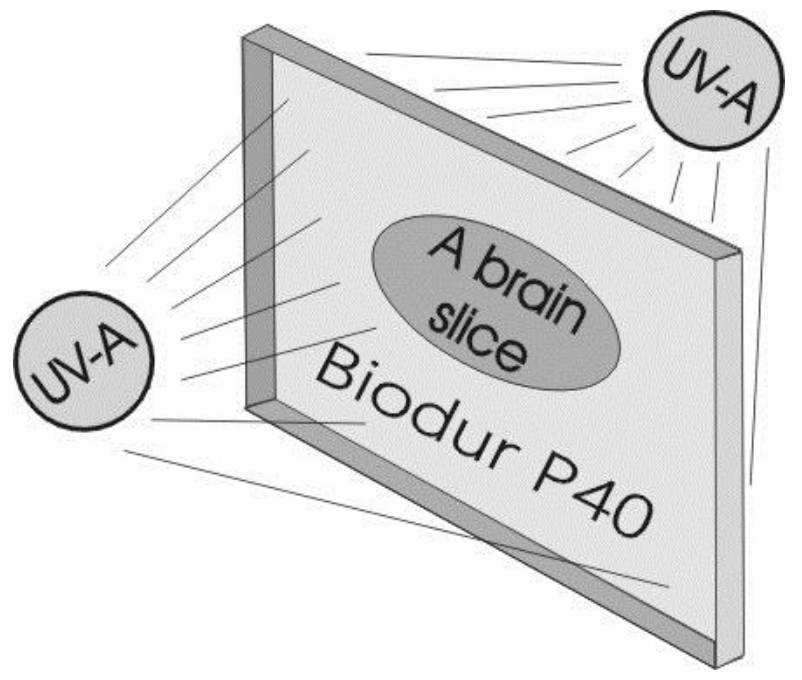

Figure 1. Scheme of UV-A lamp hardening. There are two UV sources and bilateral UV radiation on the double glass chamber.

We use the sun's rays in the early and late in the day for hardening Biodur P40 in the development of brain plates (Figure 2). The half of preparations was cured using UV-A light (1-st group) and the other preparations was cured using sunny light (second group).
The basic requirement is the intensity of solar radiation to be not high, as rapid polymerization causes shrinkage and cracking of the protective polyester film. The quality was rated visually.

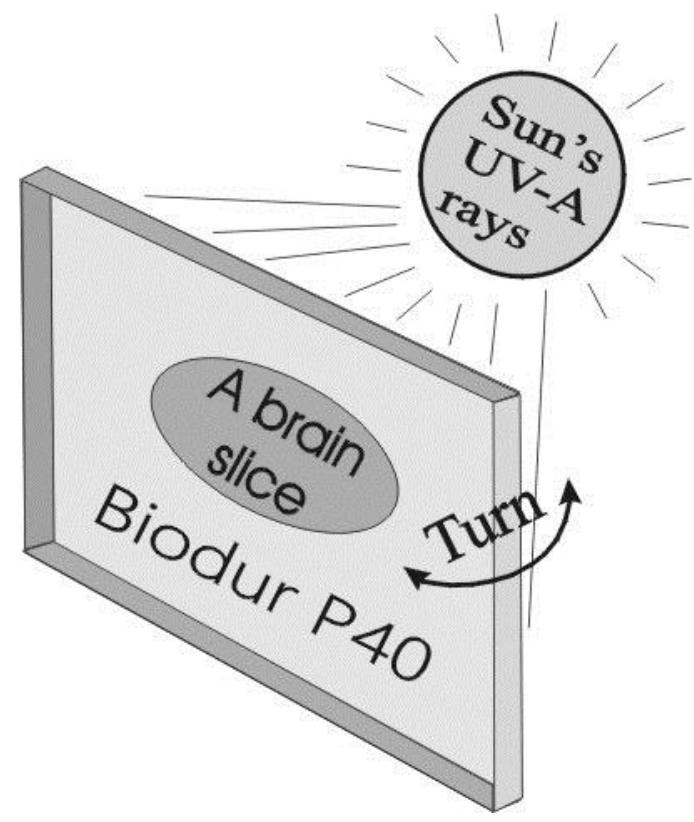

Figure 2. Scheme of UV-A sun's rays hardening. The sun is a free UV sources and double glass chamber must turn to it. 


\section{RESULTS}

The final brain slices of each group had high quality. They was transparent and had a good difference between white and grey matter. There was not a visible difference between the groups cured using unaided eye.

\section{DISCUSSION}

Thin slices allow to reduced working time for dehydration and impregnation. Weiglein (7) recommends two dehydration baths of 2-4 days, but we shorted them to one bath of 3 days. Thin scission permits us to reduce the number of immersion baths too. Üzel (1) uses two immersion baths but we reduced them to one bath for 24 hours.

After P40 plastination there is a good contrast between grey and white matter in the brain. We thing that recommendation of Ulfig (8), Bickley (9) and Suriyaprapadilok et al. (5) about using of astra blue solution for brain contrasting is unnecessary.

According to its wave-length there are three kinds of UV-light. UVA (315-400 nm); UVB (280-315 nm); UVC (100-280 nm). UVA $(315-400 \mathrm{~nm})$ is the basic hardener of polyester co-polymer Biodur P40. According WHO it is relatively harmless for human health (10).

There are 16 lamps (x60 W) in the UV source. Total electric power of this device is about $1000 \mathrm{~W}$. Its consumption is $24000 \mathrm{~W}$ for 24 hours. Sun's rays are free. The juxtaposition between groups of brain slices shows that the quality of final preparations is equally. In the first group it is the same as in the second group.

The resulting anatomical preparations are of high quality and can be successfully used for training of medical and veterinary students. That is according some authors $(11,12)$.

\section{CONCLUSIONS}

1. The quality of preparations hardened by UV-lamp and sun's rays is equal.

2. It is possible to use sunny UV-light for polyester co-polymer hardening.

3. Expenses are lower in sunny hardening of P40 technique.

\section{REFERENCES}

SIVREV D., et al.

1. Üzel, M. P35 Plastination: Experiences with delayed impregnation. The Journal of Plastination. 2013, 25(1): 9-11.

2. Weiglein A., K. Bahadori. Nerve plexuses demonstrated by the P35 technique. J Int Soc Plastination, 1996, 10(2): 4-5.

3. Von Hagens. Plastination Folder. Heidelberg University. 1995.

4. Weber W, A Weiglein, R Latorre, RW Henry. Polyester plastination of biological tissue: P35 technique, $J$ Int Soc Plastination, 2007, 22: 50-58.

5. Suriyaprapadilok L, Withyachumnarnkul B. Plastination of stained sections of the human brain: Injection Plastination 17. Comparison between different staining methods. J Int Soc Plastination. 1997, 12(1): 27-32.

6. Pashaei, S. A brief review on the history, methods and applications of plastination. Int J Morphol., 2010, 28: 1075-1079.

7. Weber, W. Sheet plastination of brain slices. J Int Soc Plastination, 1994, 8(1): 23.

8. Ulfig, N. Staining of human fetal and adult brain slices combined with subsequent plastination. J Int Soc Plastination, 1990, 4(1): 33-38.

9. Bickley, H. The staining of brain slices by impregnation. J Int Soc Plastination, 1996, 11(1): 8.

10. WHO. Non-Ionizing Radiation, (NLM clasification: QT 162.U4), http://www.who.int/uv/. Translation in Bulgarian - Institute for Geophysics, Chief Editor Prof. Nikolay Miloshev. Project "Monitoring of environment - means of assessing the risk of natural and tropogennic effects" - EMIRA, of Ministry of Education and Science, Bulgaria, No IKI $-11 / 01.09 .2005$.

11. Mansor, O. Use of plastinated specimens in a medical school with a fully integrated curriculum. J Int Soc Plastination, 1996, 11: 16-17.

12. Latorre, RM, García-Sanz MP, Moreno M, Hernández F, Gil F, López O, Ayala MD, Ramírez G, Vázquez JM, Arencibia A, Henry RW. How useful is plastination in learning anatomy? J Vet Med Ed, 2011, 34: 172-176. 